\title{
O CONTROLE LITO-ESTRUTURAL NA ORGANIZAÇÃO ESPACIAL DA BACIA HIDROGRÁFICA DO RIO TAGAÇABA - PR; UMA ANÁLISE MORFOMÉTRICA DA REDE DE DRENAGEM
}

\author{
Renata Adriana Garbossa*
}

DISSERTAÇÃO DE MESTRADO - Programa de Pós-Graduação em Geologia - UFPR

DATA DE DEFESA: 06 jun. 2003

\begin{abstract}
O objetivo deste estudo é identificar a existência e a natureza do controle lito-estrutural na organização espacial da bacia hidrográfica do rio Tagaçaba, característica de região montanhosa. Como é sabido, as propriedades lito-estruturais do substrato geológico exercem controle sobre a organização espacial da rede de drenagem; assim, pretende-se avaliar a natureza e a intensidade desse controle na organização da rede hidrográfica de uma bacia esculpida em uma área serrana. Dado que a configuração geomorfológica de uma bacia hidrográfica determina e é determinada por um conjunto de relações entre as propriedades do seu ambiente e os processos
\end{abstract}

hidrogeológicos, este estudo pode fornecer uma contribuição para melhor se compreender o funcionamento de bacias hidrográficas de regiões montanhosas. Aidentificação e compreensão da natureza do controle estrutural sobre a organização espacial interna de uma bacia hidrográfica, bem como o conhecimento de sua fisiografia, permite entender melhor suas relações com os processos hidrológicos e, portanto, também o potencial de energia das correntes fluviais. O conhecimento dessas informações contribui para a tarefa de melhor planejar o uso racional dos recursos naturais e a ocupação do solo.

`E-mail: rgarbossa@yahoo.com.br 